\title{
Comparative Analysis of Symptomatic Hypocalcemia in Term And Preterm Neonates Undergoing Continuous Phototherapy
}

\author{
Preeti Gusain ${ }^{1}$, Virendra Kumar Gupta ${ }^{1}$, Shagun Gupta ${ }^{2}$,Bhagwan Sahai \\ Natani $^{1}$, Swati Agrawal ${ }^{1}$, Narbir Yadav ${ }^{1}$, Yuktika Arora ${ }^{1}$, Dhruv Vashisth ${ }^{1}$, \\ Bhawani K C ${ }^{1}$, Kasturi Devatwal ${ }^{2}$, Pahula Verma ${ }^{2}$, Anurag Tomar ${ }^{1}$ \\ ${ }^{1}$ Department of Pediatrics, NIMS University, Jaipur(INDIA) \\ ${ }^{2}$ Department of Obstetric \& Gynaecology, NIMS University, Jaipur(INDIA)
}

\begin{abstract}
Background: Neonatal hyperbilirubinemia is one of the most common conditions confronting neonatologists daily, managed by phototherapy with its inherent complications. However, phototherapy may itself result in the development of hypocalcaemia that can cause serious complications.

Aims and objectives: To compare the occurrence of phototherapy induced hypocalcemia and its complications in term and preterm neonates.

Materials and Methods: Hospital based prospective cross sectional study performed on two hundred neonates (155 term and 45 preterm neonates) receiving phototherapy enrolled during period from $1^{\text {st }}$ feb 2015 to $31^{\text {st }}$ july 2016. Plasma bilirubin and calcium levels were determined before and after 48 hours of phototherapy and clinically assessed for features of hypocalcemia i.e. jitteriness, irritability/ excitability, lethargy and convulsions and others.

Results: Out of these 200 neonates, 155 were term and 45 were preterm neonates. After 48 hours of continuous phototherapy, serum calcium levels were significantly lowered in both term $\{62(40 \%) ; p<0.001\}$ and preterm neonates $\{24(53.33 \%) ; p<0.001\}$. Out of the 62 term neonates who had hypocalcemia, 13(20.97\%) were symptomatic and of the 24 preterm neonates who had hypocalcemia, 12(50\%) were symptomatic $(p=<.001)$.Most of the symptomatic neonates showed jitteriness $(11 \%$ term and $33 \%$ preterm) and lethargy (10\% term and $16.67 \%$ preterm), none developed apnea or convulsions.

Conclusion: Neonates after being subjected to phototherapy, develop hypocalcemia which can cause serious complications like jitteriness, lethargy, convulsions, apnea and irritability, so it requires close monitoring of calcium levels, and timely supplementation of calcium to prevent hypocalcemia.
\end{abstract}

Keywords: Neonatal hyperbilirubinemia; Hypocalcemia; Phototherapy

\section{Introduction}

Neonatal jaundice is the yellow discoloration of the sclera and skin caused by hyperbilirubinemia and is one of the most common conditions confronting neonatologists daily. About $60 \%$ of term and $80 \%$ of preterm neonates develop jaundice in the first week after birth [1]. Bilirubin encephalopathy in neonates, known as kernicterus, is a devastating brain injury, which can cause permanent neurodevelopmental handicap [2].

Phototherapy has significant role in the prevention and treatment of unconjugated hyperbilirubinemia in neonates. Continuous phototherapy can produce adverse effects such as dehydration, temperature instability, skin rashes, loose stools, retinal damage, bronze baby syndrome, redistribution of blood flow and DNA damage $[2,3,4]$. A lesser known side effect, but potential complication of phototherapy is hypocalcemia (Hunter, 2004) $[5]$.

The neonates were clinically assessed for features of hypocalcemia i.e. jitteriness, irritability/ excitability, lethargy and convulsion, as well as other complication like rash, loose stool, fever and dehydration.

Ionized calcium is required for many biochemical processes including cell membrane integrity, blood coagulation, function of cell membrane, neuromuscular excitability and cellular enzymatic activity .The mechanism of phototherapy induced hypocalcemia in neonates, although not yet well understood, but seems to be accompanied by a decrease in serum melatonin concentration, which in turn is regulated by the pineal gland. Pineal gland in normal human, however, is shown to be influenced by the diurnal light dark cycle [6].

There are still fewer studies on hypocalcaemic effect of phototherapy on the term and preterm newborns. Hence, phototherapy induced hypocalcemia is a significant problem. A few studies recommend that in order to prevent hypocalcemia due to phototherapy, babies should be given calcium as prophylaxis $[7,8]$. 


\subsection{Aims and objectives}

1) To compare the occurrence of phototherapy induced hypocalcemia between preterm and term neonates with unconjugated hyperbilirubinemia.

2) To compare the symptoms of hypocalcemia in term and preterm neonates undergoing continuous phototherapy.

\section{Methods And Materials}

\subsection{Study area:}

The study was conducted in Departments of Pediatrics \& Obstetrics \& Gynaecology in NIMS Medical College, Jaipur, Rajasthan, India.

\subsection{Study population:}

A total of two hundred neonates (155 term and 45 preterm neonates) fulfilling the criteria of jaundice and requiring phototherapy enrolled during period from $1^{\text {st }}$ feb 2015 to $31^{\text {st }}$ july 2016

\subsection{Study design:}

This is hospital based prospective cross sectional study.

\subsection{Inclusion criteria:}

1) AGA (Appropriate for Gestational Age) neonates (term and preterm) who developed hyperbilirubinemia between ages 72 hours to 2 weeks of life.

2) Neonate requiring phototherapy according AAP guidelines [9].

\subsection{Exclusion criteria}

1) Neonates with Conjugated Hyperbilirubinemia.

2) Neonates with co-morbidities like: Birth asphyxia, Septicemia, Renal failure

3) Abnormal electrolyte status detected before phototherapy

After going through detailed history and examination of neonates of AGA (Appropriate for Gestational Age) who developed hyperbilirubinemia between age 72 hours to 2 weeks of life a predesigned proforma was filled. A written and informed consent from parents or guardians was taken. Neonates fulfilling the above mentioned criteria underwent blood sampling from a peripheral vein for the estimation of serum bilirubin and serum calcium levels. Total serum bilirubin was estimated by using Jendrassik-Grof's method. Serum calcium was determined by Calcium Arsenazo III method [10].

The neonates were subjected to 48 hours of continuous phototherapy from a distance of $45 \mathrm{~cm}$ from the skin using a phototherapy unit comprising of 10 LED lamps with a wavelength range of $450-465 \mathrm{~nm}$ and a spectral irradiance between $45 \mu \mathrm{w} / \mathrm{cm}^{2} / \mathrm{nm}$ to $22 \mu \mathrm{w} / \mathrm{cm}^{2} / \mathrm{nm}$ (GE Lullaby LED Phototherapy System). During exposure to phototherapy, the eyes of the neonates were shielded to prevent retinal damage and groin of male neonates were covered to protect the genitalia.

After 48 hours of continuous phototherapy, blood samples for total serum bilirubin and serum calcium were repeated. The results of serum calcium before and after 48 hours of photoherapy were analyzed.

Hypocalcemia was considered with serum calcium less than $7 \mathrm{mg} / \mathrm{dl}$ in preterm infants and less than $8 \mathrm{mg} / \mathrm{dl}$ in term neonates[11].The neonates were clinically assessed for features of hypocalcemia i.e. jitteriness, lethargy, apnea and convulsions. All neonates having hypocalcemia were treated as per the NICU protocol for hypocalcemia in neonates [11].

\subsection{Statistical analysis}

It was performed using Quickcal (Instat) software. Paired t-test was used for comparing the calcium levels before and after 48 hours of phototherapy whereas Z-test for proportion was used to compare the various percentages of hypocalcemic neonates.

\section{Observations And Results}

The study was done on 200 neonates developing hyperbilirubinemia after 72 hours of life requiring phototherapy were included in the study. Out of these 200 neonates, 155 were term and 45 were preterm neonates. The mean chronological age was 5 days for both term and preterm neonates. The mean $\pm \mathrm{SD}$ weight of preterm neonates was $2.02 \pm 0.15$ kilogram and the mean $\pm \mathrm{SD}$ weight for full term neonates was $2.66 \pm 0.17$ kilogram.

After 48 hours of continuous phototherapy, serum calcium levels were significantly lowered in both term $\{62(40 \%) ; \mathrm{p}<0.001\}$ and preterm neonates $\{24(53.33 \%) ; \mathrm{p}<0.001\}$. 
Table no. 1 showing that out of the 62 term neonates who had hypocalcemia, 13(20.97\%) were symptomatic and of the 24 preterm neonates who had hypocalcemia, 12(50\%) were symptomatic $(\mathrm{p}=<.001)$.

Table no. 2 showing that most of the symptomatic neonates showed jitteriness (11\% term and $33 \%$ preterm) and lethargy (10\% term and $16.67 \%$ preterm), none developed apnea or convulsions (Graph-1) .

\section{Discussion}

Efficacy of phototherapy in the treatment and prevention of hyperbilirubinemia in newborn having unconjugated hyperbilirubinemia has been well established. Cord serum bilirubin (CSB) level $\leq 2 \mathrm{mg} / \mathrm{dl}$ are considered safe while $\geq 2.1 \mathrm{mg} / \mathrm{dl}$ are highly suggestive of babies who will develop neonatal hyperbilirubinemia[12].

Hunter in 2004 hypothesized that phototherapy inhibits pineal secretion of melatonin which blocks the effect of cortisol on bone calcium. Cortiso if unchecked exerts a direct hypocalcemic effect and increases bone uptake of calcium as well [5].

In most normal term infants the plasma calcium level returns to normal by 10th day of life [13].

In the present study, 45 preterms and 155 term babies enrolled were subjected to phototherapy. All the babies were more than $72 \mathrm{hrs}$ of life to avoid the effect of early onset hypocalcemia as seen in babies in early neonatal period. After 48 hours of continuous phototherapy, serum calcium levels were significantly lowered in both preterm $(p<0.001)$ and term neonates $(p<0.001)$. While no significant difference were found between these two groups $(\mathrm{p}<0.247)$.

Table no. 3 shows that in the present study jitteriness was observed in $33 \%$ of preterm and lethargy was observed in $16.67 \%$ of preterm and in the present jitteriness was observed in $11 \%$ of term neonates and lethargy was observed in $10 \%$ of term neonates study after $48 \mathrm{hrs}$ of phototherapy which is comparable to the study done by Arora et al (2014) [14]. This is suggestive that Jssssssitteriness and lethargy is main symptoms in phototherapy induce hypocalcemic newborns.

Correlation of the findings of the present study with the above mentioned studies indicates that there is a significant symptomatic hypocalcemia were found in preterm infants subjected to phototherapy.

\section{Conclusion}

Phototherapy is widely used in our clinical practice for the treatment of Neonatal hyperbilirubinemia, which is one of the common conditions as seen by paediatricians. Phototherapy induced hypocalcemia is a significant problem and there is a need for close monitoring of calcium levels in neonates subjected to phototherapy, which can leads to serious complications like Jitteriness, Lethargy, convulsions, apnea and irritability. Consideration of calcium supplementation as prophylaxis may be done in neonates subjected to phototherapy.

\section{Acknowledgement}

Source(s) of support in the form of grants, equipment, drugs or all of these: NONE Declaration on competing interests: competing interests: NONE

Funding: NONE

Table-1: Comparative Analysis Of Symptomatic Hypocalcemia In Term And Preterm Neonates

\begin{tabular}{|l|l|l|}
\hline Hypocalcemia & Preterm(n=24) & Term(n=62) \\
\hline Symptomatic & $12(50 \%)$ & $13(20.97 \%)$ \\
\hline Asymptomatic & $12(50 \%)$ & $49(79.04 \%)$ \\
\hline
\end{tabular}

P- Value $=<.001$

Table 2: Distribution Of Cases According To Symptoms In Symptomatic Hypocalcemia

\begin{tabular}{|l|l|l|}
\hline Symptom & Preterm $(\mathbf{n}=\mathbf{1 2})$ & Term $(\mathbf{n}=\mathbf{1 3})$ \\
\hline Jitteriness & $\mathbf{8}(\mathbf{3 3 . 3 3 \%})$ & $7(11.29 \%)$ \\
\hline Lethargic & $4(16.67 \%)$ & $6(09.67 \%)$ \\
\hline Total & 12 & 13 \\
\hline
\end{tabular}

Table 3: Comparison Of Percentages Of Symptomatic Hypocalcemic Preterm And Term Neonates after 48 Hrs Of Phototherapy.

\begin{tabular}{|c|c|c|c|c|}
\hline Symptoms & \multicolumn{2}{|c|}{ Jitteriness } & \multicolumn{2}{|l|}{ Lethargy } \\
\hline Cases & Preterm & Term & Preterm & Term \\
\hline Arora Et Al(2014) $)^{49}$ & $35 \%$ & $10 \%$ & $10 \%$ & $4 \%$ \\
\hline Present Study & $33 \%$ & $11 \%$ & $16.67 \%$ & $10 \%$ \\
\hline
\end{tabular}


Graph 1 : Distribution Of Cases According To Symptoms In Symptomatic Hypocalcemia

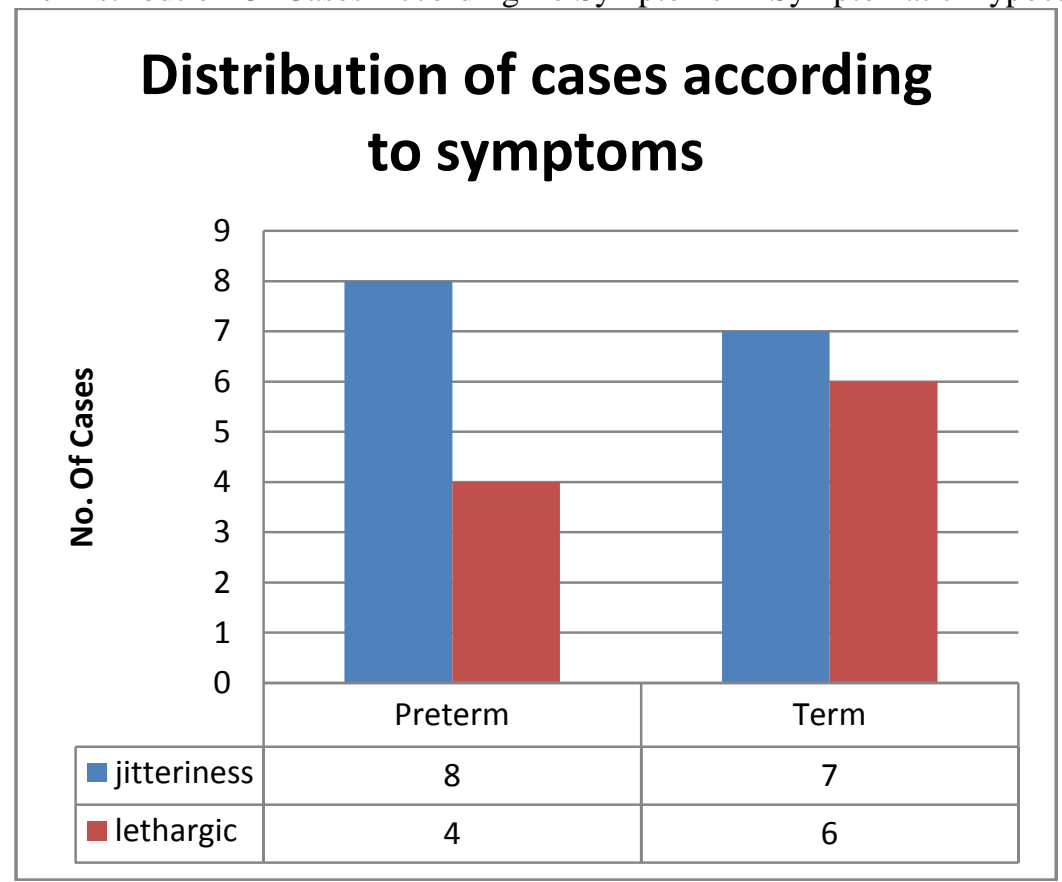

\section{Bibliography}

[1]. Rennie J, Burman-Roy S, Murphy MS. Neonatal jaundice:summary of NICE guidance. BMJ. 2010;340:c2409.

[2]. Maisels MJ, McDonagh AF. Phototherapy for neonatal jaundice. N Engl J Med 2008;358:920-928

[3]. Hansen TW. Twists and turns in phototherapy for neonataljaundice.ActaPaediatr 2010;99:1117-1118

[4]. Kliegman M. The fetus and the neonatal infant, in:Behrman R, Nelson textbook of pediatrics. 19 ${ }^{\text {th }}$ ed. Saunders Philadelphia 2011; 603-612.

[5]. Hunter KM: Hypocalcaemia. In: Manual of Neonatal Care. JP Cloherty, EC Eichenwald, AR Stark (Eds.); 5thEdn.; Lippincott Williams \& Wilkins, Philadelphia. 2004;pp.579-588.

[6]. Hakanson, D.O., R. Penny, and W.H. Bergstrom, Calcemic responses to photic and pharmacologic manipulation of serum melatonin. Pediatric Research 1987;22: 414-416.

[7]. Yadav RK, Sethi RS, Sethi AS, Kumar L, Chaurasia OS. The Evaluation of Effect of Phototherapy on Serum Calcium Level. People's J of Scientific Res. 2012; 5(2): 1-4.

[8]. [8] Karamifar H, Pishva N, Amirhakimi GH. Prevalence of Phototherapy Induced Hypocalcemia. Iran J Med Sci. 2002; 27(4): 166168 .

[9]. Management of hyperbilirubinemia in the newborn infant 35 or more weeks of gestation. American Academy of Pediatrics Subcommittee on Hyperbilirubinemia. Pediatrics 2004; 114: 297-316.

[10]. Janssen JW et al. Arsenazo III: an improvement of the routine calcium determination in serum. Eur J Clin Chem Clin Biochem. 1991 Mar;29(3):197-201.

[11]. Jain AJ, Agarwal RA, Sankar MS, et al. Hypocalcemia in the Newborn. AIIMS-NICU Protocols. 2010

[12]. Gupta S,Gupta V.et al.Neonatal hyperbilirubinaemia after induction of labour with oxytocin and cord serum albumin is compared with cord serum bilirubin as a risk indicator International Journal of Biomedical Research 2016; 7(7): 435-438.

[13]. Altirkawi, K. and H.J. Rozycki, Hypocalcemia is common in the first $48 \mathrm{~h}$ of life in ELBW infants. Journal of Perinatal Medicine 2008;36: 348-353.

[14]. Arora SA, Narang GS, Singh GS. Serum Calcium Levels in Preterm and Term Neonates on Phototherapy. J. Nepal Paediatr. Soc. January-April,2014; 34(1):24-28. 